\title{
Tele-operator performance and their perception of system time lags when completing mobile robot tasks
}

\author{
David A, Sanders \\ School of Engineering \\ University of Portsmouth \\ Portsmouth, UK \\ david.sanders@port.ac.uk \\ Martin Langner \\ Research and development \\ Chailey Heritage \\ North Chailey, UK \\ mlangner@chf.org.uk \\ Alexander Gegov \\ School of Computing \\ Un iversity of Portsmouth \\ Portsmouth, UK \\ alexander.gegov @port.ac.uk
}

\author{
David Ndzi \\ School of Engineering \\ University of Portsmouth \\ Portsmouth , UK \\ david.ndzi@port.ac.uk
}

Heather M. Sanders

Peter Symonds College, Winchester

United Kingdom

heatherms1999@yahoo.co.uk

\author{
Giles E. Tewkes bury \\ School of Engineering \\ University of Portsmouth \\ Portsmouth, UK \\ giles.tewkesbury@port.ac.uk
}

\begin{abstract}
E ffects of motion lag on the capability of a teleope rated mobile-robot operator are in vestigated. Lags can occur through communication delays as telc-operated mobile robots work at a distance or because of a lack of parallel computing power as robots are enhanced with add itional systems. This work concentrates on time lag in a tele-operated mobile robot system and investigates when a mobile robot operator might begin to perceive a lag in the movement of a mobile robot. A threshold of permissible lag is established for mobile robot operators that relates to the maximum time lag before an operator noticed a lag.
\end{abstract}

Keywords-lag; tele-operated; mobile; motion, robot.

\section{I NTROD UCTION}

The effect of time delays i s investigated. Performance is studied using a tele-operated mobile-robot in a variety of environments. A n umbilical cable connected a joystick to the robot and the robot had ultrasonic sensors on board that could be switched in or out and that could help a tele-operator to avoid obstacles.

The joystick was used to control the mobile-robot and teleoperators drove the robot along a sequence of routes both with and without sensors to assist.

After briefly describing the sensors and mobile-robot hardware, then testing is described and results are reported. Finally there is some discussion and some suggestions for future work.
Main conclusions are that an operator may accomplish more without any sensors providing any help in straightforward and undemanding environments, but they need sensors as the environment becomes more complicated or time delay is introduced and that there is a maximum level of time lag beyond which a human operator becomes aware that there is a lag and that maximum level can be measured.

Failure rates increased significantly as time delay was introduced and the sensors were not engaged. Performance improved with the sensors as environments became more complicated but in both cases there was a level of time delay at which an operator would notice the lag. It might be especially useful if the sensors could be switched in to assist at the moment when the time lag is beginning to be noticed.

In more complex surroundings then tele-operators were quicker and had fewer collisions when using sensors to help them, especially time delays were introduced and then extended. That built on some results from [1-2) who suggested global performance was better if tele-operators were allowed to act in their own space and without sensors interfering.

Testing took place within and around the University of Portsmouth. The tests were made more complicated for each group of investigations by adding to the number of objects (usually cardboard boxes) and including some slopes. Umbilical systems were assessed because they may be used in places like the nuclear industry (2) as the mobile robot can be pulled out of the environment by the umbilical cord if the robot fails. 
Time lag from an input given by a joystick to a requested output to the motor controller is a factor that influences driving performance [3]. Performance can be affected if an operator perceives a time lag. This work found that an onset amount of perceived lag exists tmaxlag, when a tele-operator will real ize that there is a time lag in the system. The operator may also be sensitive to a phase lag because as frequency increased, the phase lag of the system i ncreased. That is being investigated in some further work but resu lts from that testing are inconclusive at the time of writing.

The length of time lag when the operator begins to notice the lag is tmaxlag, The Perception Time. Time lags have been investigated in [4-5] but the perception of the lag has seldom been studied, exceptions being [2] who mentioned the idea and [3] that investigated time lag for a robot arm. The perception of time lag has never been properly investigated for teleoperated mobile robots.

\section{BACKGROUND}

Several systems help human operators execute their tasks i n remote or hazardous environments [6-9] and investigations have taken place to explore the way tele-operators cooperate and act together with mobile robots [I 0-12] but they didn't take into account any time delays. If a tele-operator is separated from a remote site then a time delay can exist. A 11 delays add distortion [1 3] and degrade performance [14]. Tele-operation systems have a tendency to find some middle ground between clarity and stability margin [15]. Some approaches concerning the control of tele-operated structures with a constant time delay have been described [16-17] and for vaiying time delays in [3] and [18-19].

Mobile-robots can find unstructured environments difficult [20-26]. Tele-operation means that robots can be controlled and directed from a safe place that is away from hazards [27]. Wheeled mobile robots are studied in the research described here because they are still the most common [22-24] and [28].

Manual controls are usually used to direct a tele-operated mobi le-robot. The master has often included a joystick as the input device [22-24]. The input is usually a low current device and the mobile robot (or other target system) is a much higher $\mathrm{h}$ igh current device, for example DC-servo motors. They are sometimes controlled remotely via radio or an umbilical cable.

Research has attempted to improve tele-operation for inspection and maintenance purposes, especially where there are dangerous hazards or in foul or hostile surroundings [27]. Autonomous control may not always be needed or wanted and human tele-operators can steer mobile-robots instead. A human driver can often drive along a route more efficiently than a computer. Very complicated manipulations can be accomplished using a wheeled base with manipulator arm mounted on it [29-31].

There are emergency situations when time is critical and it is especially $\mathrm{i}$ mportant that there is efficient interaction between human- and robot. The research described here investigates that interfaci ng and collaboration with variable amounts of time delay being introduced during testing.
Tele-operation has tended to be open loop. Tele-operators indicate direction and a mobile-robot moves in that direction. Disturbances can include variances between the wheels or tractors or dissimilar responses to different surfaces and gradients, $\mathrm{i} \mathrm{n}$ addition to ti me delays. Tele-operators have reacted to those $d$ isturbances and corrected the path and trajectory.

Tele-operation is described in [32] and guided vehicles in [33] and two influential papers are by Sheridan [8] and [34].

The tele-operated mobile robot used in this work is described in the next Section. It had a sensor system that could be switched in or out.

\section{THE TELE-OPERATED MOBILE ROBOT}

Fig. I is a picture of the mobile robot base.

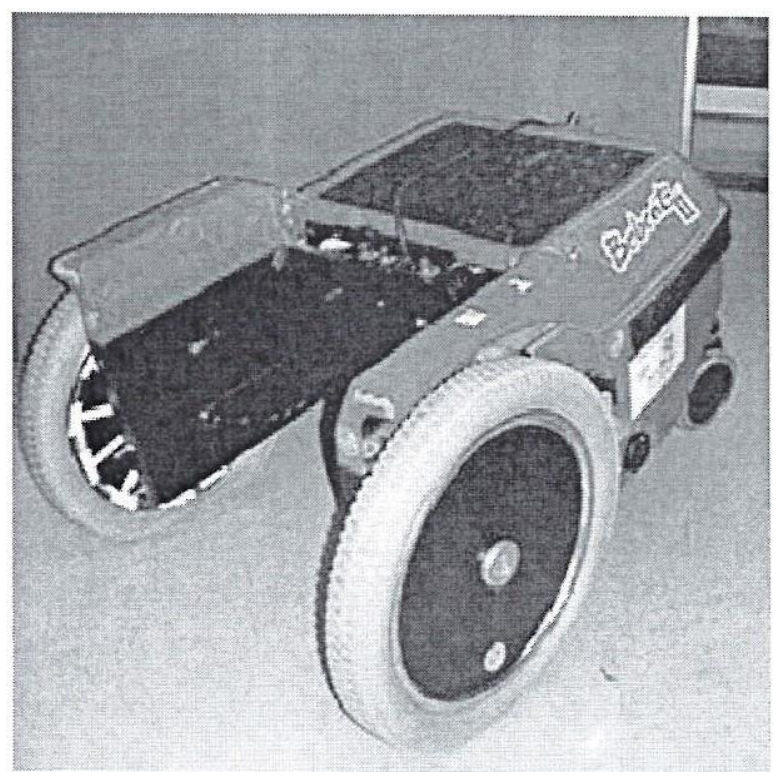

Fig. I. Bobcat II mobile robot base

The big wheels at the front were DC-Motors driven by DC servo-amplifiers. A j oystick was used to provide the desired $\mathrm{d}$ i rection and speed. The tele-operated mobile robot was adapted to incorporate additional control systems and sensors.

Two trailing castors were at the back and the driving wheels were at the front. U ltrasonic sensors were fixed above each

drive wheel. Varying the difference between the rotat ional speeds of each of the two driving wheels steered the robot base.

Ultrason ics have been extensively used for mobile robots and tele-operated mobile robots [2], [9] and [22-26] and wheelchairs [27-33]. Ultrasonics were selected because they were straightforward, robust and trouble-free. Pairs of transmitters and receivers were installed above the driving wheels and facing forwards.

Ultrasonic echoes were translated into a $\mathrm{m}$ inimal depiction of the situation in front of the mobile robot. Integral functions were appl ied to the joystick input so that the inclination to rotate away from objects could be overridden by the human teleoperator. Algorithms used to mix the inputs to the tele- 
operated mobi le robot from the joystick and sensors have been described i n [22-26). The mobi le robot was controlled via "flyby-w ire" [1 1 1] and [42). The connection between the tel eoperated mobile robot and the joyst ick was disconnected (Fig. 2).

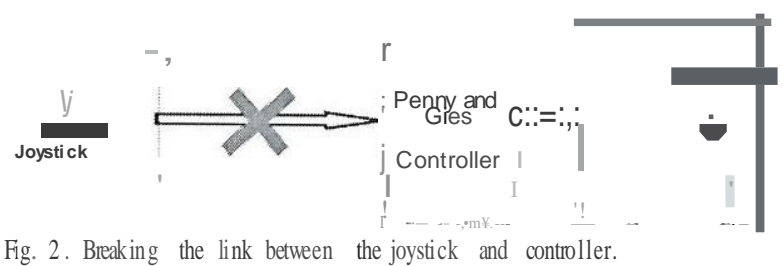

Fig. 2. Breaking the link between the joystick and controller.

Instead, a computer managed the control of the mobile robot base (Fig. 3). The ultrason i c sensors were triggered by the computer and then it adjusted the path of the robots if required. Sensors could be switched off and thejoystick input coul $\mathrm{d}$ be sent straight to the De Servo-controller. In that state, the robots reacted directly to input from thejoyst icks.

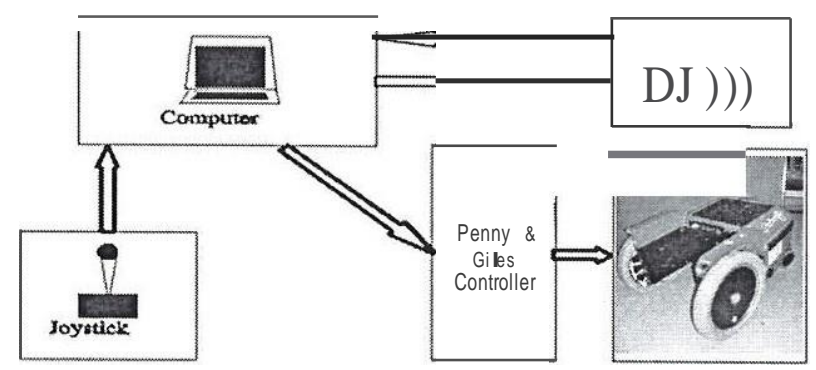

Fig. 3. Computer control by "fly-by-wire".

The computer applied three ru les: ( I ). Tele-operator stayed in control. (2) Sensors only modified a mobile robot path when they needed to. (3) Mobile robot trajectories were even and flowing.

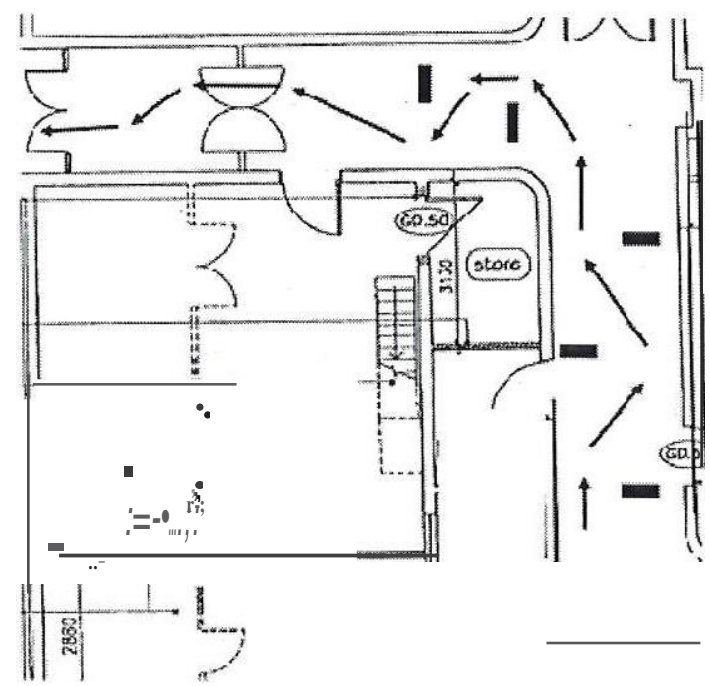

Fig. 4. Compl icated Corridor 3.

\section{TESTING}

The tele-operator drove the mobile robot and the computer could introduce a time delay, $\mathrm{h}$, to the joystick input commands so that the actual commands to the DC-Servo Amplifiers was late [2]. Instead if the actual joyst ick signal, v 1, a delayed signal, $\mathrm{vd}$, was sent to the servo amplifiers and therefor the drive motors for the mobile robot.

An example of a test route is shown in Fig. 4. It is a map of Complicated Corridor number 3. Arrows depict the route of the mobile robot and dark rectangles show the pos itions of movable objects placed there for the test. The corridor contained 2 sets of double doors. Only one of the doors of each was opened and fixed and a robot was forced to zig and zag to go beyon d the door. Fig. 5 shows the average of $t$ ime taken for tele-operator to complete a variety of routes.

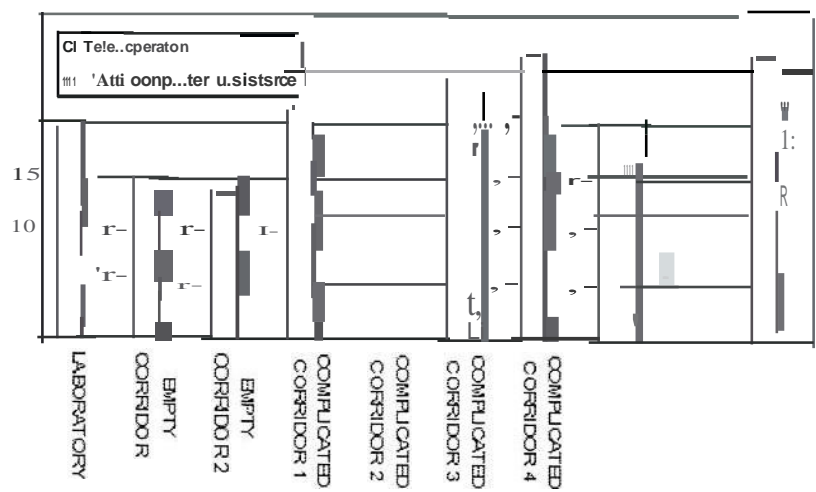

Fig. 5. Average of times to complete various routes.

The vertical scale shows the averaged times in seconds to finish successfu 1 runs. The simpler routes were completed faster when the tele-operators did not have any assistance from the sensors. More complicated routes are on the $r$ ight of the bar graph (for example a corridor with obstacles and doors or outdoor environments), and the tele-operators completed those tasks more quickly when they were assisted by the computer and sensors. Fig. 6 shows the averages of the time taken to complete a variety of routes after a delay of a second was

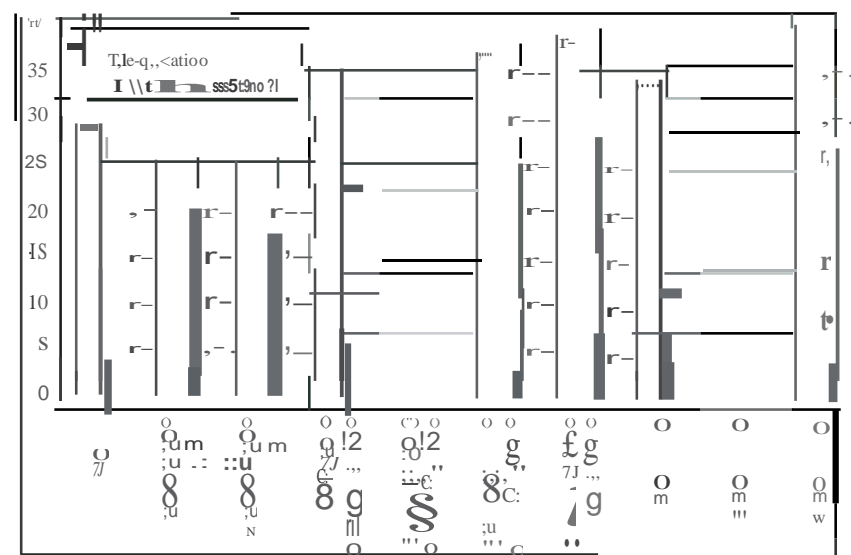

instituted.

Fig. 6. Averages of timestocomplete various routes with a systemdelay of one second. 
Fig. 7 shows a tele-operator steering the robot base through a doorway.

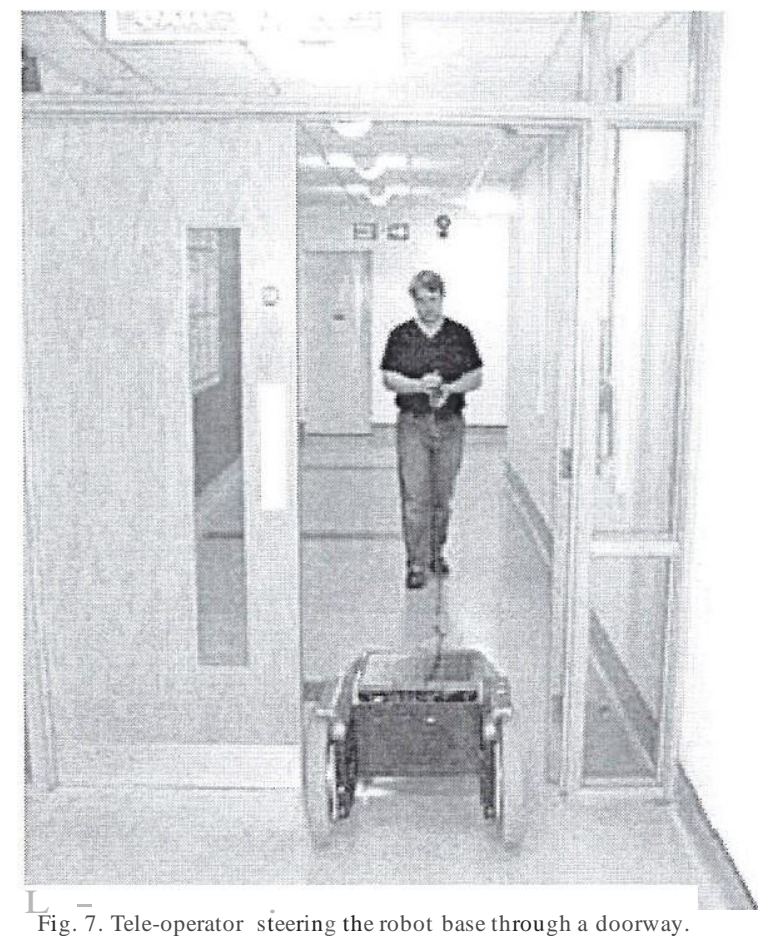

The tele-operated robots were assessed in safe environments and then in various situations. The lengthiest experimental routes were 30 metres long. Volunteer teleoperators quickly learnt how to steer the mobile-robot and how it responded. They could apply appropriate control signals and could evaluate brakin g distances.

The tests were undertaken using a delay to introduce arbitrary $t$ ime lags [43-44]. Tel-operators completed driving tests along various routes and the effect of the delay was as sessed to expose an onset of a perception of time lag at tmaxlag. A magnitude estimation technique was applied [3] and [45].

\section{A. Magnitude Estimation}

Commands from the joystick were delayed by vary ing amounts before being sent to the mobile robot. Randominputs were produced to test the generator using:

$$
\mathrm{Gs}(\mathrm{s})=\exp (-\mathrm{As})
$$

Magnitude Estimation [3] del ivered measurable assessments of the effects from introducing time lags. Most importantly, the perceived $t$ ime lag was provided by this calculation. The technique exposes effects due to stimulations and is a quantitative as sessment of psychological reactions, for example the effect due to the introduction of a time lag. Magnitude es timation is a sensory assessment commonly used in ergonomics [45).

Stevens s howedin [46) that a psychologicalquantity IJlwith a degree of physical st imul us ST was related by Stevens' power law(2) [3] and [46]:

$$
\mathrm{q},=\mathrm{GF} \times \mathrm{ST}^{\prime \prime}
$$

Where: 'fl is a psychological value, ST is the size of the stimulus, and GF is a gain factor.

The physicals timulation is time lag. Psychological value, $\mid U l$, could then be calculated by relating the time lag to the effect of the time lag.

Experimentation was similar [3] in their work with a teleoperated surgical robot.

The delay generator operated at $0.1 \mathrm{~Hz}$ and a metronome made a noise every I O seconds so that the sound and the delay generator were synchronized. Delay times were selected from ten possible levels in a random order. The levels and the delays are shown in table I. The magnitude of the effect of time lag was noted.

TABLE !

\begin{tabular}{|l|c|c|c|c|c|}
\hline Level & 1 & 2 & 3 & 4 & 5 \\
\hline $\begin{array}{l}\text { Time delay in } \\
\text { milliseconds }\end{array}$ & I & 2 & 3 & 4 & 5 \\
\hline Level & 6 & 7 & 8 & 9 & 10 \\
\hline $\begin{array}{l}\text { Time delay in } \\
\text { milliseconds }\end{array}$ & 7 & 10 & 14 & 19 & 25 \\
\hline
\end{tabular}

Fourteen men and women $\mathrm{m}$ aged their early twenties volunteered to drive the mobile robot for a series of tests.

The mobile-robot successfully coped with obstacles during testing; the computer systems automatically avoided collisions.

The perception of the time lag for an input frequency of 0.1 $\mathrm{Hz}$ was converted to a logarithmic value. That produced a continuous curve that specified the response after a teleoperator had perceived the lag.

A line was fitted to the resu lt $\mathrm{s}$ that was an estimate of the relationship. That result indicated that the perceived lag $t$ ime was $70 \mathrm{~ms}$. Equation (3) is the relation between the time lag of more than $70 \mathrm{~ms}$ and the magnitude of the time lag effect.

$$
\mathrm{q},=25 \times \mathrm{ST}^{035}
$$

When the lag was $<70 \mathrm{~ms}$, the tel-operators didn't notice. The delay time at which an operator noticed a lag was attained for input frequencies between $0.1 \mathrm{~Hz}$ to $\mathrm{I} \mathrm{Hz}$ and (2) was evaluated.

The relationship between time lag, the magnitude of the effect of the lag and the approximate power function was considered.

The phase lag of the dead-time system was:

$$
L \mathrm{GUw})=-\mathrm{roA}
$$

So, input angular frequency, co, deten 1 lined the phase lag when a tele-operator distinguished the time lag. A was the perceived time lag.

Perceived time lag, perceived phase lag and the power index are 1 isted in table II.

Phase lag $=$ input frequency * 360 * lag time 


\section{TABLE I I}

\begin{tabular}{|c|c|c|c|}
\hline $\begin{array}{l}\text { Input } \\
\text { frequency } \\
(\mathbf{H z})\end{array}$ & $\begin{array}{l}\text { Perceived } \\
\text { lag time } \\
(\mathbf{m s})\end{array}$ & $\begin{array}{l}\text { Perceived l ag } \\
\text { phase }(\mathbf{d e g})\end{array}$ & $\begin{array}{l}\text { Power } \\
\text { index }\end{array}$ \\
\hline 0.1 & 80 & -2.88 & 0.35 \\
\hline 0.2 & 70 & -5.04 & .4 \\
\hline 0.5 & 50 & -9 & .41 \\
\hline $\mathrm{I}$ & 25 & -9 & .35 \\
\hline
\end{tabular}

Some data for $0.2 \mathrm{~Hz}$ is shown in Fig. 8 .

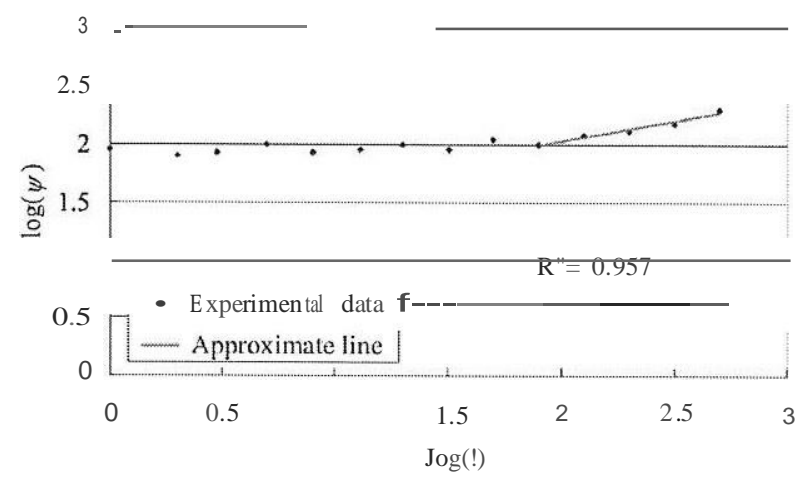

Fig. 8. Log If plotted against $\log$ ST for $0.2 \mathrm{~Hz}$.
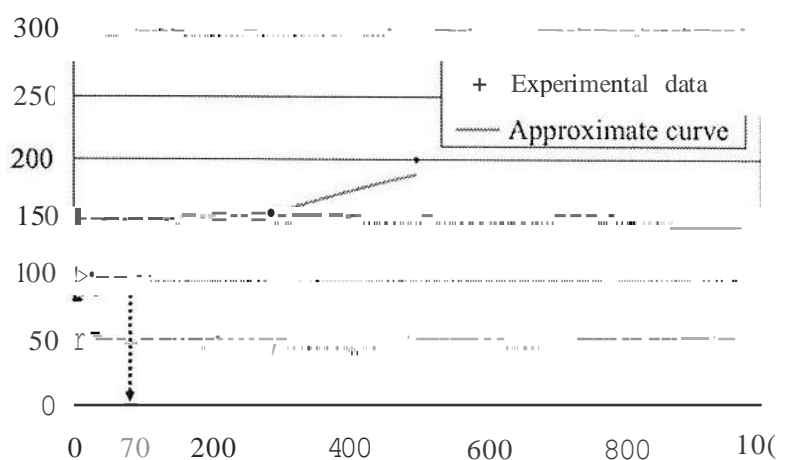

Fig. 9. Estimate of the relationship showing a perceived time Jag of $70 \mathrm{~ms}$. The $Y$ axis is' and the $X$ axis is: $1 \times 10^{\circ}$ s

\section{DISCUSSION}

Magnitud e estimation was used to produce a quantitative evaluation of the effect of time lag. Table II shows that input frequency, $w$, affected the perceived lag; if $w$ increased then perceived lag time decreased, so that at slow speeds it was d ifficult for an operator to perceive any time lag.

Figure 9. Shows the line drawn to estimate the relationship. The result indicated a perceived time lag of $70 \mathrm{~ms}$. When the delay was greater than tmaxlag, then an operator would notice the lag. Power index after the operator noticed was 0.36 (on average) and that value $\mathrm{d}$ id not depend on $w$. From this result, it was concluded that perceived lag time differs between each input frequency but after perception the magnitude of the time lag effect had no correlation to $w$.

As power index $<\mathrm{I}$, the effect became less sensitive as lag increased.

The threshold of perception may also related to phase lag so that if a tele-operated mobile robot operator does not perceive a lag, phase lag still needs to be less than perceived phase lag.

\section{CONCLUSION}

The relationship between time lags and their effect was investigated and some results presented. A perceived threshold for time lag, tmaxlag, was estimated. Once an operator began to notice a delay, then the scale of the effect increased (2). The power index averaged a value of 0.36 .

Perceived time lag, 'l', changed depending on input frequency, $w$. 'l' reduced as $w$ increased. Reliabil ity of 'l' depended on tmaxlag, To improve reliabi 1 ity, more tele-operators will need to be tested in the future with the mobile robots.

A Student's t-test compared the means of the completion time samples. Average (mean), ;:was calculated with standard deviation (S) to evaluate population mean $\mu$ and variance $\mathrm{a}^{2}$. Because pairs of tests and results were used, paired-samples could be used for statistical testing. Pairs of results were used, one set of data with assistance from the sensors and one set without any assistance.

Pairing removed much of the randomness introduced when using human operators $\mathrm{i} n$ testing because the same person completed each set of tests that were compared, so 1 ike was being compared with like. Results were significant and the pairedsamples test showed that driving without any sensors and driving with sensors were significantly different. There was a $95 \%$ probabi 1 ity that the results could not happen by chance, that is $p<0.05$

Tele-operators executed their tasks more quickly when they did not have any sensors assisting them in simple environments. When the situation was more complicated, or there were longer time delays, then tele-operators performed better with sensors to assist them. The two main findings are that sensors should not be used in simple environments with good visibility but shou ld be reserved for restr icted areas with poor views and that it proved to be possible to estimate a perceived threshold for time lag.

\section{FURTHER WORK}

The system used a delay after the joystick and before sending the signal to the mobile robot motors. Other sorts of delay could be introduced and that could be investigated in the future.

The delays are being investigated in other applications, including teaching systems [47-50], automated systems [51 -60] and especially tele-operation [61], [62]

Additionally, the perceived effect of phase lag has not really been fully considered. Tele-operators may also be sensitive to phase lags because as $W$ increased, system phase lag increased. 


\section{REFERENCES}

[I] P. Milgram, S. Zhai, D. Drascic and J. Grodski, Applications of augmented reality for human-robot communication, Proc' IEEE/RSJ Int Conf on Int' Robots \& Systems, vol. 3 (26-30) pp. 1467-1472. 2003.

[2] D.A. Sanders, Analysis of the effects of time delays on the teleoperation of a mobile robot in various modes of operation, IND ROBOT, vol. 36, no. 6, pp. 570-584. 2009.

[3] K. Toyoda, J . Okamoto and M.G. Fujie, The correlation between perception of motion Jag and phase lag in tele-operation robot system, Proc. IEEE Int' Conf on Robotics \& Biomimetics, Thailand, 2008.

[4] S. Chang, et al, Time Delay Analysis in Tele-operation System, Proc. IEEE Int' Workshop on Robotics \& Human Interaction , pp. 86-91, 1999.

[5] K. Kawamura, T. Tajima, J. Okamoto, and M. G. rujie, Development of Real-time Simulation for robotic tele-surgery, Journal of Japan Society of Computer Aided Surgery, vol. 7, no. I, pp. 7-14, June 2005

[6] D.A. Sanders, The modification of pre-planned manipulator paths to improve the gross motions associated with the pick and place task ROBOTICA, vol. 13 pp.77-85. 1995.

[7) T.B. Sheridan, Tele-operation, telerobotics and telepresence: A progress report, Control Eng. Pract. 3(2), pp 205-214. 1995.

[8] T. Sheridan, Humans and Automation: System Design and Research Issues. John Wiley and Sons. 1995.

[9] D.A. Sanders, Comparing speed to complete progressively more difficult mobile robot paths between human tele-operators and humans with sensor-systems to assist. ASSEMBLY AUTOM, vol. 29, no. 3, pp. 230 248. 2009.

[J O) D.A. Sanders, M. Langner M and G.E. Tewkesbury, Improving wheelchair-dr iving using a sensor system to control wheelchai r-veer and variable-switches as an alternative to digital-switches or joyst icks. IND ROBOT, vol. 37, no. 2, pp. 157-167, 2010.

[11] D.A. Sanders and A. Baldwin, X-by-wire technology, Total Vehicle Technology Conference, pp. 3-1 2. 2001

[12) D.A. Sanders, Controlling the direction of walkie type forklifts and pallet jacks on sloping ground. ASSEMBLY AUTOM, vol. 28 (4), pp 317-324. 2008

[13] P. Fiorini and R. Oboe, Internet-based telerobotics: Problems and approaches, Proc' of ICAR'97, Monterey, CA, pp. 765-770. 1997.

[14) J.P. Richard, Time-delay systems: An overview of some recent advances and open problems, Automatica vol. 39, pp 1667-1694. 2003.

[15] D.A Lawrence, Stability and transparency in bilateral tele-operat ion, IEEE Trans. Robot. Autom. Vol. 9 (5). 1993.

[16] W. Kim, B. Hannaford and A. Bejczy, Force reflection and shared compliant control in operating telemani pulators with time delay IEEE Trans. Robot. Autom. vol. 8(2), 176-185. 1992.

[17] G. Niemeyer and J.J Slotine, Stable adaptive tele-operation . IEEE J Ocean. Eng. vol. 16(1), 152-162. 1991

[I8] G. Niemeyer and J.J S1 otine, Towards force reflecting tele-operation over the Internet, Proc' of the I EEE Int' Conf on Robotics and Automation, Leuven, Belgium (ICRA'98), pp. 1909-1915. 1998.

( 19] E. Slawinski, V. Mut and J.F. Postigo, Tele-operation of mobile robots with time-varying delay. Robotica, vol 24, pp. 673-681. 2006.

[20) B.L. Luk, D.S. Cooke, S. Galt, A.A Collie and S. Chen, Intelligent legged climbing service robot for remote maintenance applications in hazardous environments, Jrnl of Robotics and Autonomous Systems, vol. 53/2, pp. 142-52. 2005

(21J B. Rooks, Plotting future UK robotics research Programmes, I ND ROBOT vol. 33 (3), pp. 165-169. 2006

[22] DA Sanders, GE Tewkesbury and DC Robinson, Simple expert systems to improve an ultrasonic sensor-system for a tele-operated mobile-robot. SENSOR REV, vol. 31, no. 3, pp. 246-260. $201 \mathrm{I}$.

[23] D.A Sanders and I.J. STOTT, Analysis of failure rates with a teleoperated mobile robot between a human tele-operator and a human with a sensor system to assist. Robotica Journal. 20 I I .

(24] D Sanders, G. Tewkesbury and J. Graham-Jones,Simple rules to modify pre-planned paths to improve gross robot motions associated with pick \& place assembly tasks. ASSEMBLY AUTOM, vol. 31 (I) 2011.
[25] D.A. Sanders, Comparing abil ity to complete simple tele-operated rescue or maintenance mobile-robot tasks with and without a sensor system. SENSOR REV, vol. 30, no. I, pp. 40-50. 20 I0.

[26) D.A. Sanders, J. Graham-Jones and A. Gegov, Improv ing ability of teleoperators to complete prog ressively more difficult mobile robot paths using simple expert systems and ultrason ic sensors. IND ROBOT, vol. 37, no. 5, pp. 43 1-440. 2010.

(27] I. Stott and D. Sanders, New powered wheelchair systems for the rehabil itation of some severely disabled users, Int Jrnl REHAB RESEARCH vol. 23 (3), pp. 149-1 53. 2000.

[28] D. Sanders and I. Stott, A new prototype intelligent mobility system to assist powered wheelchair users IND ROBOT vol. 26 (6), pp. 466-475. 1999.

[29] M.J Goodwin , D.A. Sanders and G.A. Poland et al, Navigationa 1 assistance for disabled wheelchair-users, proc' of Euromicro Conference 95 vol. 43, pp. 73-79. 1997

(30] D. Sanders, Analysis of the effects of time delays on the teleoperat ion of a mobile robot in various modes of operation, IND ROBOT vol. 36 (6) pp. 570-584. 2009 .

(31 J D. Sanders, I. Stott, J Graham-Jones et al, Expert system to interpret hand tremor and prov ide joyst ick position signals for powered wheelchairs with ultrasonic sensor systems, IND ROBOT vol. 38 (6), pp. 585-598. 20 II.

(32) D.A. Sanders, N. Bausch, 1-1. Liu, et al, Improving Steering of a Powered Wheelcha ir Using an Expert System to Interpret Hand Tremor, Proc' Intelligent Robotics \& Applicat ions, Pt I vol. 9245 pp. 460-471. 2015.

[33) D. Sanders and I. Stott, The use of virtual reality to train powered wheelchair users and test new wheelchair systems, Internationa 1 Journal of Rehabilitation Research vol. 23(4), pp. 321-326 . 2000.

[34] D. Sands, Cost effective robotics in the nuclear industry. IND ROBOT, vol. 33, No 3, pp I 70 - 173. 2006.

[35] T. Nakamura and K. Satoh, Development of an omni-directional mobile robot using traveling waves based on snail locomot ion. IND ROBOT, vol. 35 (3), pp. 206-210. 2008.

[36] B.L Luk, A.A. Collie, D.S Cooke and S.Chen Walking and climbing service robots for safety inspection of nuclear reactor pressure vessels. Measurement \& Control vol. 39 (2), pp. 43-47. 2006

[37) B. Luk, K. Liu, A. Collie, D. Cooke \& S. Chen, Tele-operated climbing and mobile service robots for remote inspection and maintenance in nuclear industry, IND ROBOT, vol. 33, No 3, pp. 194-204. 2006.

[38] M.J Bakari and D.W Seward, Human arm-like mechanical manipulator the design and development of a multi-ann mobile robot for nuclear decommissionin g. Proc' 3rd Int, Conf Infonnatics in control, automation and robotics - Robotics and Automation, pp. 168-175. 2006.

[39) B.P DeJong E.L Faulring, J Edward Colgate, M.A Peshk in, H. Kang, Y.S Park and T.F Ewing, Lessons learned from a novel tele-operation test-bed . . IND ROBOT, vol. 33, No 3, pp. 187 - 193. 2006.

[40] R. Rocha, A.Cunha, J. Varandas, and J. Dias, Towards a new mobility concept for cities: architecture and program ming of semi-autonomous electric vehicles. IND ROBOT, vol. 34, No 2, pp. 142 -149. 2007

[41] T. Sheridan, Telerobot ics, automation, and human supervisory control. Cambridge, MA: MIT Press. 1992

[42] D.A. Sanders, I.J.Stott and M.J. Goodwin, A software algorithm for the intelligent mixing of inputs to a tele-operated vehicle. J SYST ARCHITECT, vol. 43 no. 1-5, pp. 67-72. 1997.

(43) K. Toyoda, et al, Dexterous master-slave surgical powered robot for minimally invasive surgery-Intuit ive interface and interchan geabl surgical instruments, Proc. of 201h Int' Congress and Exhibition, Computer Assisted Radiology and Surgery, pp. 503-504, 2005.

(44) K. Toyoda , et al, Development of heart-beat compensation surgical robot for totally endoscopic Off-pump Coronary Artery Bypass Graft, Proc. of the J71h CISM-IFToMM symposium, pp. 343-350, 2008

[45] T. Fukuda, et al, Ergonomics guide, Scientist Inc. 2004

[46) S.S. Stevens, On the psychoph ysical law, Psychological Review, vol. 64(3), pp.153-1 81, 1957.

[47] S. Chester, G. Tewkesbury, D. Sanders et al, New electronic multimedia assessment system, Web Information Systems and Technologies vol. I, pp. 320-324. 2007 
[48) J. Bergasa-Suso, D.A. Sanders, G.E. Tewkesbury, Intelligent browserbased systems to assist Intemet users, $\mathbb{E E E}$ Transactions on Education vol. 48 (4), pp. 580-585. 2005

[49) D.A. Sanders and J. Bergasa-Su so, Inferring Learning Style fromthe way students interact with a computer User Interface and the WWW, IEEE Transactions on Education vol. 53 (4),pp. 613-620.2010.

[50) S. Chester, G. Tewkesbury, D. Sanders et al, New electronic multimedia assessment system, Proc' of 2"' Int Conr on Web Information Systems \& Technologies (WEBIST); Society, E-Business and EGovernmen t/ E-Learning,pp. 320-324.2006.

(51) D.A. Sanders, Recognizing shipbuildin g parts using artificial neural net works andFourierdescriptors, Proc' of theIMechE Part 8-Journal of Engineering Manufacture vol. 223 (3),pp. 337-342. 2009.

[52] D. Sanders, Y. Tan, I. Rogers et al, An expert system for automatic design-for-assembly, ASSEMB AUTO, vol. 29(4),pp. 378-388. 2009.

(53) D. Sanders and A. Gegov, Al tools for use in assembly automation and some examples of recent applications, ASSEMBLY AUTOM, vol. 33 (2), pp. 184-194. 2013.

(54) D. Sanders, G. Tewkesbury, D. Ndzi et al, Improving aut omatic robotic welding in shipbuilding through the introduction of a corner-finding algorithm to help recognise shipbuilding parts, Journal of Marine Science and Technology, vol. 17 (2),pp. 231-238.2012.

[55) M. But ar But ar and D. Sanders et al, MeasuringPerformance of Reverse Supply Chains in a Computer Hardware Company. I EEE Int' Conr on Management of Innovation \& Tech, pp. 489-494. 2014
(56] D.C. Robinson, D.A. Sanders, E. Mazharsolook, Ambient intelligence for optimal manufacturin $\mathrm{g}$ and energy efficiency, ASSEMBLY AUTOM, vol. 35 (3), pp. 234-248. 2015

[57] D.A. Sanders, G. Tewkesbury, A. Gegov, elal, Fast Transformations to Provide Simple Geometric Models of Moving Objects, Proc' Intel ligent Robotics \& Applications (ICIRA 15),PtI vol.9244,pp. 604-615. 2015.

[58] Sanders, DA; Urwin-Wright, SD; Tewkesbury, GE; et al, Pointer device for thin-lilm transistor and cathode ray tube computer screens, Electronics Letters vol. 41 (16), pp. 894-896. 2005

[59] D.A. Sanders, B.P. Haynes, G.E. Tewkesbury, et al, The addition of neural net works to the inner feedback path in order to improve on the use of pre-trained feed forward estimators, Mathemat ics and Computers in Simulation vol. 41 (5-6), pp. 46 1-472. 1996.

(60) D.A. Sanders and G.E. Tewkesbury, A pointer device forTFT display screens that detennin es position by detecting colours on the display using a colour sensor and an Artificia 1 Neural Network, DISPLA VS vol. 30 (2), pp. 84-96. 2009.

(61] D.A. Sanders, J. Graham-Jones and A. Gegov, Improving ability of teleoperat ors to complete progressively more difficult mobile robot paths using simple expert sy stems and ultrasonic sensors, IND ROBOT, vol. 37 ( 5), pp. 431-440. 2010.

[62) D.A. Sanders, 1. Stott, D.C. Robinson et al, Analysis of successes and failures with a tele-operated mobile robot in various modes of operation, ROBOTICA vol. 30, pp. 973-988. 2012. 